\title{
Distopia, angústia de aniquilamento e a radical poética das relações
}

\author{
Ana Kiffer ${ }^{a}$ (D) \\ Mariana Patrício Fernandes ${ }^{b}$ (D)
}

\begin{abstract}
RESUMO
O presente artigo pensa a distopia sob a égide da angústia de aniquilamento (MBEMBE, 2016) e busca refletir como tal noção desafia o surgimento de poéticas da relação (GLISSANT, 1990) como modo de criação dos espaços literário (BLANCHOT, 1955), utópico e heterotópico (FOUCAULT, 2009) em sociedades cujo passado colonial, e as incursões de cunho autoritário, perpetraram-se ao longo de séculos, como é o caso da sociedade brasileira. A hipótese primordial é a de que, nesses contextos, os espaços de distopia se estabelecem como o início, e não como o fim de tudo, vindo a ser um dos operadores fundacionais de um lugar (utópico ou heterotópico?) inventado pelo outro, o colonizador. A angústia de aniquilamento é a ferramenta primordial para a construção desse lugar e dessa cena (que a literatura irá propagar), e dos laços sociais e os efeitos de divisão espacial (social) e discursiva subsequentes. $O$ artigo buscará, nesse sentido, colocar em questão a noção contemporânea de distopia - muito presente nas
\end{abstract}

Recebido em: 27/11/2020 Aceito em: 26/02/2021

a Pontíficia Universidade Católica do Rio de Janeiro, Programa de Pós-Graduação em Literatura, Cultura e Contemporaneidade, Rio de Janeiro, RJ, Brasil. E-mail: anakiffer@gmail.com

b Universidade Federal do Rio de Janeiro, Departamento de Ciência da Literatura, Programa de Pós-Graduação de Ciência da Literatura, Rio de Janeiro, RJ, Brasil. E-mail: maripatricio22@gmail.com

\section{Como citar:}

KIFFER, A.; FERNANDES, M.P. Distopia, angústia de aniquilamento e a radical poética das relações. 
narrativas sobre o fim do mundo e na aparição dos messianismos negativos da contemporaneidade no contexto específico da formação das sociedades coloniais, mas não sem deixar de observar alguns estratos estético-politicos nos quais uma poética da relação burla esse desenho nas sociedades póscoloniais.

Palavras-chave: Distopia. Poética da Relação. Espaço literário. Brasil.

\section{Apresentação}

Entendemos que para se pensar a distopia, que hoje insurge como fio e tecido organizador de uma nova ordem do discurso (FOUCAULT, 1996) nas sociedades contemporâneas, seria necessário voltar atrás e compreender algumas das formações primordiais dos laços que, num dado momento e em condições muito específicas, "uniram" e "desuniram" os diferentes povos do mundo. Para nós, essa formação anterior, ainda hoje presente sob distintos aspectos nas sociedades contemporâneas, indica que, no caso de muitas sociedades traçadas pela colonialidade, a distopia insurge como cena primordial e fundacional, e não posterior, porvir ou final. Essa é a nossa hipótese central: a de que a fundação dos espaços coloniais se ergueu sobre estratos que já começavam pela ameaça do fim e pelo gesto de um certo findar, como sendo o próprio gesto organizador do seu "início".

Nosso olhar vai buscar reler algumas dessas camadas discursivas que recolocam a ideia do fim como princípio desestruturante de um início. Vamos buscar os gestos do findar em seu gérmen. Vamos buscar pensar de que forma tais camadas operam um modo de produção do espaço que impossibilita o engendramento de relações de coexistência, impondo, por conseguinte, uma série de procedimentos de exclusão e de invisibilidade que estancam a possibilidade de toque e de aproximação entre os diferentes corpos, aludindo, por conseguinte, às cenas de extermínio, aniquilamento ou devoração do outro, do diferente. 
${ }^{1}$ Sobre o espaço heterotópico como sendo o definidor dos espaços pós-coloniais e sobre essa hipótese específica ver : KIFFER, Ana. O Brasil é uma heterotopia. São Paulo: N-1 edições, 2020. (textos pandêmicos) Disponível em: https:// www.n-1edicoes.org/ textos/125. Acesso em: 26 nov. 2020
Essa hipótese central acabará nos levando a dois caminhos que, mesmo que não encontrem aqui o espaço para aprofundamento, merecem serem deixados entreabertos ao final do texto. Um deles obrigará a rever criticamente alguns aspectos sobre como aparecem os discursos atuais sobre a distopia. O outro exigirá pensar que o discurso colonizador organiza tipos de relações específicas, nos espaços coloniais, entre distopia, utopia e heterotopia. Essa organização espaçodiscursiva se faz majoritariamente sob dois vértices: tecendo o espaço colonial como sendo o da utopia, ou o da heterotopia. A utopia passa a ser a representação mesma de um espaço idílico; e idílico passa a ser um modo de relação sem conflitos, sem crispação ou, quando conflitivo, camuflado ou heroicizado, mas nunca próximo ao real extermínio fundador e formador dos espaços coloniais. A heterotopia, segundo Foucault (2009, p. 22), é aquela que engendra a criação e a representação de verdadeiros contra espaços, que nas sociedades modernas se configuram como contra espaços de desvio das normas constitutivas dos espaços instituídos da vida. Ora, o que se nos parece crucial perceber, e que não foi apontado por Foucault, é que esses desvios (transgressões e desencaminhamentos) que surgem nas sociedades modernas não existiriam sem a estrutura e o braço das sociedades coloniais. ${ }^{1}$ Sob esse aspecto, as heterotopias coloniais acabam sendo o contra espaço de desrecalque e liberação dos instintos mais recônditos do colonizador (MBEMBE, 2020, p. 112). Isso nos faz observar que os modos de relação que se instauram nessas sociedades tendem ainda hoje a oscilar entre esses dois polos. Tal oscilação, entre ser a encarnação de um corpo-território do sonho (utopia), ou das transgressões (heterotopia), atingiu diretamente a constituição do espaço artístico-literário. Não por acaso, tal espaço vem comumente sendo alocado como um dos espaços utópicos nas sociedades ocidentais, que ora legitima o espaço colonial como seu correlato utópico, ora investe nele como o seu outro, heterotópico, lugar de profusão orgástica dos corpos que nutrem de erotismo e de morte o imaginário branco e ocidental até hoje.

Por isso, é possível reconhecer em diferentes autores e épocas dos espaços artístico-literários da colonialidade fontes e traços que se dedicaram, sob diversos prismas, a desenhar a narrativa de uma pretensa "união" idílica entre os povos, 
enquanto acontecimento apaziguado e não conflitivo, como de fato o foi. Para além dessas narrativas apaziguadoras e camufladoras dos conflitos e extermínios, decerto mais localizadas temporalmente (mesmo que não exclusivas de uma época), debatem-se todos os outros que escrevem desde esses espaços. Debatem-se porque encetaram ou buscaram em algum momento a formação de poéticas relacionais entre os diferentes povos constitutivos do Todo-Mundo (GLISSANT, 1997), mesmo quando não encontraram os traços de seu extermínio. Debatem-se porque se torna difícil escrever sobre o que não teve lastro sem parecer irreal ou idílico. Debatem-se porque torna-se complexo não falsear o encontro que de fato nunca ocorreu. Debatem-se porque anseiam por esse encontro, mesmo quando não possuem repertório ou imaginário para a sua realização. Debatem-se porque sofrem, mostrando que, muitas vezes, a fartura da palavra para eles disponível é também a marca da fratura e da pobreza da experiência não compartilhada.

Por tudo isso, entendemos que as poéticas relacionais, mesmo quando em sua impossibilidade, acabam sendo a marca constitutiva dos espaços artístico-literários nas sociedades traçadas pela colonialidade. Elas também tecem uma determinada ordem do discurso que ajuda a redesenhar a cena primordial de suas formações, que irrigaram o imaginário literário. Não se restringindo ao período histórico do romantismo e a sua tarefa explícita de corroborar para a fundação dos Estado-nação coloniais, essas cenas adentram os mais diferentes estilos e épocas literárias. Decerto, o romantismo, o modernismo e o realismo social dos anos trinta insurgem como momentos de reorganização-chave dessa narrativa sobre a formação social e sobre a formação dos laços entre as diferentes culturas e povos. O modernismo europeu é invadido e construído, sob vários aspectos, através do fantasma do Outro - irracional, não civilizado, bestial ou libertário, na maior parte das vezes fundindo esse Outro (inconsciente) aos povos africanos e ameríndios - verdadeiros significantes materiais, introduzidos como fantasmas que ganham corpos através das máscaras africanas, das mitologias indígenas, e do imaginário pictórico e literário da riqueza natural e ao mesmo tempo amedrontadora das florestas da América. Assim como o realismo social europeu, que interrogando o seu campesinato, 
a sua força e forma rude, abre a brecha da interrogação sobre a formação social da própria sociedade brasileira, ela mesma muito próxima ao colono português nas Américas, que se desenha na figura do homem sobranceiro, fonte e origem do homem cordial em Buarque de Holanda (1995, p. 29-41). Além das inúmeras personagens que cunham o nordestino bravo e forte, povo do êxodo e da fome, fonte insurrecta do imaginário de um povo por vir e, ao mesmo tempo, correlato a essas figuras coloniais que aqui de um modo ou de outro recriamos e/ou reproduzimos.

Mas não somente desses grandes momentos históricoliterários e artísticos são feitas as narrativas que organizam os corpos e os espaços nas sociedades coloniais. Aqui, gostaríamos de destinar o nosso olhar tanto para momentos menos vistos, quanto para a análise crítica que entrelaçará o passado ao presente. Em ambos os casos, a perspectiva que os une é aquela cuja ênfase da análise e da seleção dos trechos, obras e autores se faz sob a égide de uma poética da relação. Inspirada nas contribuições de Édouard Glissant (1990), a poética da relação será entendida aqui como esse conjunto de gestos escriturários que visam formular o contato, o conflito, o encontro e o desencontro entre os diferentes povos que fundam os territórios coloniais. Priorizaremos não as narrativas apaziguadoras do imaginário colonial, mas justo aquelas que não temeram se confrontarem como o fosso para com o fosso, o buraco e o vazio que o silêncio das narrativas apaziguadoras acabou desenhando. Silêncio sobre o extermínio, a escravidão e o abuso dos povos negros e indígenas que foi provocando e adensando a fissura social e o seu trauma, inviabilizando tantas vezes aquilo mesmo que essas narrativas tanto desejavam: construir uma nação independente.

A ênfase das nossas escolhas recai sobre a exclusão e ou apagamento radical do povo negro, como ator e autor dessa poética da relação e os conflitos que, em alguns momentos, isso colocou para o escritor que buscava, de algum modo, abordar a constituição dessa relação extirpada, manca, faltosa ou ausente. O outro traço dessa escolha diz respeito ao modo como situamos tais autores: através do gesto radical em direção a uma poética da relação. Neles, o problema primordial dessas sociedades recai todo ele sobre as potências ou não das relações que elas possibilitam ou impedem. Relações entre vivos e não 
vivos, humanos e não humanos e línguas distintas. A relação é o que os desafia, orientando-os e desorientando-os em sua busca poética por um imaginário que se quer possível, mesmo quando percebido ou sentido como impossível, intratável ou pouco abordado pelos espaços literários e de vida que os constituíram e formaram.

A matriz da relação nos permite abordar o traço que aqui nos interessa: o da desorientação, do abismo ou da angústia de aniquilamento como efeito dessa ausência de lastro relacional. Isso que, na base da formação cultural e política das sociedades coloniais, embaralham as categorias espaço-temporais e desorganizam a discussão sobre as distopias atuais. Como a matriz relacional está ausente, o gesto relacional implicará numa radicalidade tal que desorienta a narrativa, no caso de $A$ paixão segundo G.H. de Clarice Lispector, ou que exige a criação de uma verdadeira memória profética do próprio passado extirpado, no caso de A barca aberta do martiniquense Édouard Glissant. Em ambos, o gesto do findar é de fato o princípio formador das sociedades marcadas pela colonialidade, embaralhando ou mesmo desfazendo a ideia de que a distopia é o tempo que ingressamos depois que "tudo" findou.

As análises desses textos fazem avultar o fato de que o passado colonial continua sendo a matriz relacional do mundo ocidental ainda hoje. Tal matriz não termina na formação dos Estados-nação, tampouco nas guerras coloniais. Ela perpetuase na própria organização do sistema capitalista que, como apontam diferentes autores (MBEMBE, 2016; BUCK-MORSS, 2011), encontra no sistema escravocrata a sua fórmula germinal. Por isso, e sobretudo quando pensamos a partir de países que ainda se inserem numa grande faixa de dependência (econômica e cultural), refletir sobre a distopia é também refletir sobre a negação primordial do direito à vida de alguns, que vem constituindo a formação de uma imensa maioria dos povos colonizados. Como se, nesse caso, o fim se enunciasse como princípio. Princípio, visto aqui tanto em seu sentido organizador das relações, quanto em seu aspecto temporal: assim começamos, ou assim ingressamos no mundo civilizado e ocidental - sem futuro.

Para pensar essa máquina relacional primordial recorreremos à noção de angústia de aniquilamento, tal qual formulada por Achille Mbembe em Políticas da inimizade (2016). 
Ela opera como laço fundacional das relações de colonialidade, entrelaçando constantemente o tempo colonial ao tempo presente:

O muro de separação é suposto resolver a questão do excesso de presença, essa que, se pensa, está na origem dos sofrimentos insustentáveis. Recobrir o sentimento de existir depende, desde aí, da ruptura com esse do qual a ausência, até mesmo o desaparecimento puro e simples, não será vivido como perda. Isso é admitir que entre ele e nós não há nenhuma parte comum. A angústia de aniquilamento está no cerne dos projetos contemporâneos de separação. (MBEMBE, 2016, p. 63, tradução nossa).

Seguiremos essa pista, como modo de compreender os desafios ainda não enfrentados, as diferenças e nuances que nos caracterizam, e também eventuais saídas encontradas através de novas maneiras de um poder-dizer (KIFFER, GIORGI, 2019, p. 53) que atravessará tempos distintos e diferentes obras e autores aqui lidos.

O nosso intuito é menos o da análise de um objeto estético específico, e mais a aposta numa hipótese fundamentalmente teórico-crítica sobre como a angústia do aniquilamento (que permite ver a distopia como fundação dos espaços coloniais) forjou um modo relacional doentio nessas sociedades. E, logo, de que maneira os gestos estéticos e artísticos buscam (mesmo quando fracassam) burlar essa matriz através de uma radical poética da relação. Fornecer ferramentas e pensar a distopia do nosso tempo e espaço exige, no nosso caso, voltar ao tempo passado, e ainda deslizar sobre um espaço de produção discursiva heterogêneo, que mesmo que chamemos ainda aqui de espaço literário, ele o será, como todo outro espaço colonial, pensado, nesse texto, de forma instável. Enquanto não conseguirmos reorganizar de modo mais inclusivo os nossos espaços, suas nomenclaturas, de origem colonial, estarão também sob suspeição.

\section{Distopias}

A distopia, em seu sentido etimológico, mas também usual, indica a perda dos espaços e da função imaginária da utopia. Sob esse aspecto toda distopia está numa relação negativa com uma determinada utopia. $\mathrm{O}$ avultar da distopia 
${ }^{2}$ Em “O futuro será negro ou não será: Afrofuturismo versus Afropessimismo - as distopias do presente" (2018), Kênia Freitas e José Messias analisam a relação entre futurismo e pessimismo a partir da experiência da diáspora africana, na qual o passado e o presente estão conectados por meio de um duplo trauma: o da escravidão (passado) e o da perseguição (presente). "De uma perspectiva negra a distopia seria o comum e não a exceção." (FREITAS; MESSIAS, 2018, p. 411). Semelhante visão pode ser reconhecida no curta-metragem "República" de Grace Passô, criado durante a pandemia da Covid-19, em 2020, com base num sonho no qual o Brasil nunca teria existido. Ainda: a própria ideiatítulo do ensaio de Ailton Krenak (2019) sugere um campo de saber no qual adiar o fim do mundo foi desde sempre primordial. Leia-se primordial também em seu sentido temporal. no mundo contemporâneo foi fazendo com que ela perdesse essa relação específica com uma determinada utopia e insurgisse, de maneira autônoma, quando não totalitária, como elemento auto organizador de si mesma. Essa autoorganização não apenas desvincula o uso da distopia da utopia que lhe corresponde, como passa a caracterizar distopia todo e qualquer discurso sobre o fim. Ainda mais além: passa a inserir os discursos sobre o fim como modelo organizador das sociedades contemporâneas. Sob esse prisma dois eixos de interrogação são fundamentais: num deles torna-se necessário (re)localizar espaço-temporalmente a relação entre distopia e utopia. Noutro, vale interrogar sobre os fundamentos que fazem com que a distopia crie hoje essa nova ordem do discurso acerca das sociedades contemporâneas insuflando-as de seu próprio fim. Valeria aqui interrogar a quem pode interessar essa ordem do discurso? Ou: quais são os principais agentes mantenedores do imaginário do fim?

Para tanto, a primeira pergunta seria: a distopia age hoje sobre todos os vivos? Seus efeitos são os mesmos, independente de nossa localização geográfica e de nossa história no mundo? Podemos falar que o mundo distópico afeta a brancos e a negros exatamente da mesma maneira? Jovens europeus, americanos e brasileiros estão sobre a mesma linha distópica? ${ }^{2}$ Deveríamos, antes de afirmarmos como a distopia entrelaça o mundo atual, traçar uma cartografia da distopia no mundo contemporâneo? Obviamente, a sequência dessas perguntas indica a própria trilha por onde anda a nossa reflexão, e não a impossível tarefa de que responderemos cada uma delas no espaço deste texto. Nessa trilha está o rastro daquilo que entendemos como sendo primordial: a consciência de que a distopia não afeta a todos os povos, muito menos da mesma maneira.

E esse prisma que revira, localiza e nuança a distopia, indica que do nosso ponto de vista, o do Eixo-Sul do mundo, que tende a ser visto, dada a hegemonia do Norte, a partir de uma perspectiva de cabeça pra baixo, o fim e o findar foram os gestos constitutivos das sociedades autóctones, pobres e negras que povoaram a América. O fato de que o fim do mundo insurge nesses espaços mentais, imaginários, geográficos e relacionais, como metáforas de um porvir anterior, como uma mitologia de origem, ou uma profecia do passado, usando os termos de Glissant, nos obriga, no mínimo, a rever essa 
ordem mundial e esse investimento homogêneo em torno dos discursos sobre o fim nas sociedades atuais.

Em circunstâncias nas quais o passado foi roubado ou forjado por outrem, como é o caso das sociedades coloniais, é o imaginário que provém a sua gente a sua dimensão constitutiva e estrutural de mundo. Fora isso, o seu próprio fim ou extermínio, aqui já não mais metafórico, porém real, poderá se concretizar, carregando, no entanto, a dimensão temporal de um imenso desde sempre. É nessa cena que entram em ação a angústia de aniquilamento e o convite a uma poética da relação.

\section{Angústia de aniquilamento}

Em sociedades onde a presença do outro se constitui de forma central, nevrálgica e lapidar, e, ao mesmo tempo, negada ou constantemente exterminada, como foi o caso das sociedades coloniais, onde os corpos destruídos das pessoas escravizadas, dos indígenas - povo primordial do continente americano, eram logo substituídos por outros (MBEMBE, 2016, p. 66), a angústia de aniquilamento será o modus operandi e estruturante de suas relações internas. A combinação entre a presença extremada do outro e a sua exclusão e extermínio é o que funda, ou o que está na base dessa sensação de que o outro fora de mim - encarna o inimigo, hostil e, logo, constantemente apartado e a ser exterminado. Da senzala às favelas e aos muros fronteiriços das sociedades contemporâneas, Mbembe vê uma linha de continuidade que faz com que a angústia de aniquilamento constitua as políticas de inimizade como modo de estar hoje no mundo. Essa angústia é de tal modo constitutiva que ela opera de todos os lados. Em sua leitura de Fanon, Mbembe mostra como o homem doente é todo aquele que foi obrigado a se constituir sem lugar no mundo, esse homem sem lugar é privado de relações de reciprocidade, logo do encontro autêntico com outro homem (MBEMBE, 2016, p. 14). Ora, uma sociedade, como a sociedade colonial, privada da possibilidade de promover esse encontro, ou apenas situando o encontro sob a égide do desencontro, ou do encontro com o outro enquanto inimigo ou ameaça, configura-se, toda ela, como um tecido social doente, se seguirmos a pista de Fanon. O outro, assim produzido, é o agente real de uma angústia sem precedentes, angústia de aniquilamento. 
É ainda sob o desafio da relação que a angústia de aniquilamento se configura não apenas como prática política edificadora dos muros, favelas, e espaços heterotópicos de extermínio, ou como modus operandi do Estado, ou das relações intersubjetivas no tecido social. De fato, seu impacto mais profundo se dá sobre o desenho do próprio imaginário, constituído através das estéticas da existência, dos espaços artístico-literários, e insuflando o tecido social desse impossível encontro com o outro. Fazendo desse impossível a própria ruína da sociedade, e de sua emancipação quiçá a única possibilidade de saída, de escrita e de vida.

A relação e o encontro com o outro precisam de um solo comum, um espaço compartilhado no qual os corpos possam coexistir em condição de isonomia, em que seja simultaneamente possível olhar e ser olhado. Em Nonrepresentational theory: space, politics, affects (2008), Nigel Thrift pensa uma teoria do espaço que leve em conta os aspectos não conscientes e afetivos da experiência espacial, e a possibilidade do jogo (play) como sendo um caminho de engajamento mais receptivo à estranheza do mundo. Essa dimensão do espaço torna possível traçar outros circuitos que escapam aos regimes de visualidade instituídos e marcados pelas configurações autoritárias do poder. Esse processo não estaria ligado somente ao caráter visual da experiência, mas a um conjunto de relações.

Seria possível dizer que em sociedades marcadas pela colonialidade, como a sociedade brasileira, essa relação entre o espaço e o olhar tem sido amplamente codificada e vigiada desde o início, de modo a impedir a relação. Em "Racismo e sexismo na cultura brasileira" (1984), Lélia Gonzalez analisa os modos pelos quais a violência produzida pela escravidão e pela colonização engendrou uma série de recalcamentos que tinham como consequência a negação do racismo e, logo, a recusa da condição humana ao homem e, sobretudo, à mulher negra. Segundo Gonzalez, a forma como essa neurose se articula, além de interferir nas já mapeadas desigualdades socioeconômicas, impacta as subjetividades atravessadas por processos marcados pela desvalorização e pelo silenciamento. Aí não há comunidade possível, e a mitologia que apresenta o Brasil como uma democracia racial serviria apenas, nas palavras da autora para "ocultar algo além daquilo que mostra" (GONZALEZ, 1984, p.6). O que aí se oculta é justamente as 
condições de opressão em que vive a população negra no Brasil desde a escravidão. Aproximando-se da psicanálise e da noção lacaniana de denegação, Gonzalez lança mão da separação entre consciência e memória - "o que a consciência exclui, a memória inclui" (GONZALEZ, 1984, p. 7) - para pensar os mecanismos de recalcamento e também as formas de resistência e recriação da história, e da presença da cultura negra e africana no Brasil.

Os modos de separação e exclusão que levam ao recalque do racismo brasileiro passariam, ainda segundo González, por uma naturalização da desigualdade que organiza os espaços físicos desde o período da escravidão:

As condições de existência material da comunidade negra remetem a condicionamentos psicológicos que têm que ser atacados e desmascarados. Os diferentes índices de dominação das diferentes formas de produção econômica existentes no Brasil parecem coincidir num mesmo ponto: a reinterpretação da teoria do "lugar natural" de Aristóteles. Desde a época colonial aos dias de hoje, percebe-se uma evidente separação quanto ao espaço físico ocupado por dominadores e dominados. O lugar natural do grupo branco dominante são moradias saudáveis, situadas nos mais belos recantos da cidade ou do campo e devidamente protegidas por diferentes formas de policiamento que vão desde os feitores, capitães de mato, capangas, etc., até à polícia formalmente constituída. Desde a casa grande e do sobrado até aos belos edifícios e residências atuais, o critério tem sido o mesmo. Já o lugar natural do negro é o oposto, evidentemente: da senzala às favelas, cortiços, invasões, alagados e conjuntos "habitacionais" dos dias de hoje, o critério tem sido simetricamente o mesmo: a divisão racial do espaço. (GONZALEZ, 1984, p. 10).

Em Necropolítica (2018), Achille Mbembe também dá ênfase ao modo como, no sistema de dominação colonial, a ideologia dominante também depende de uma operação espacial que determina zonas onde a violência é liberada, fazendo do espaço "a matéria prima da soberania e da violência que ela carregava consigo" (MBEMBE, 2018, p. 39). A condição do escravo implica uma tripla perda: a perda de um lar, a perda de direitos, e a perda de estatuto político, impossibilitando qualquer possibilidade de comunidade. Se a noção de soberania que orienta o Estado colonial não se baseia na autonomia dos povos, "dotados de razão", mas sim da permissão em matar 
e da decisão de quem deve matar e de quem deve morrer, ela se realiza e assume a sua forma a partir da ideia de ocupação territorial:

A "ocupação colonial" em si era uma questão de apreensão, demarcação e afirmação do controle físico e geográfico inscrever sobre o terreno um novo conjunto de relações sociais e espaciais. Essa inscrição de novas relações espaciais ("territorialização") foi, enfim, equivalente à produção de fronteiras e hierarquias, zonas e enclaves; a subversão dos regimes de propriedades existentes; a classificação de pessoas de acordo com diferentes categorias; extração de recursos e finalmente, a produção de uma ampla reserva de imaginários culturais. Esses imaginários deram sentido à instituição de direitos diferentes para diferentes categorias de pessoas, para fins diferentes no interior de um mesmo espaço [...] Soberania significa ocupação, e ocupação significa relegar o colonizado a uma terceira zona, entre o estatuto de sujeito e objeto (MBEMBE, 2018, p. 39).

Poderiam a arte e a literatura criar brechas nessas fronteiras simbólicas e concretas que invadem o imaginário colonial? Seria possível falar com Maurice Blanchot em um "espaço literário" no qual as identidades se desfazem, habitado pelo impessoal (BLANCHOT, 1955, p. 21)? E nesse espaço literário, a relação acontece? O encontro? Algo próximo ao toque, em que as diferenças entre os corpos não sejam deglutidas, aniquiladas? Se toda relação precisa de uma cena, e falar em cena é falar em chão, em terra, e se dentro dos territórios coloniais, falar em terra é falar em propriedade, seria possível pensar em um espaço literário que seja um lugar de desapropriação, no qual os pés tocam o mesmo chão, na mesma relação com ele?

No Brasil da primeira metade dos anos 1960, em um processo que seria interrompido pela ditadura civil-militar, as ligas camponesas reivindicavam reforma agrária e a escritora Carolina Maria de Jesus andava pelas ruas do campo e da cidade em busca, simultaneamente, de um espaço para plantar, morar e também de um lugar para falar na cena literária. Seu livro Quarto de despejo vendeu milhares de cópias poucas semanas após o lançamento, dando a sensação de que o processo de fundação de um espaço finalmente liberto da opressão colonial estaria em vias de acontecer. No entanto, o sucesso editorial e o alívio financeiro revelaram-se para a 
autora, como escreve depois no livro Casa de alvenaria, de 1961, insuficientes para construir esse espaço de relação e troca com uma elite dominante que parece não querer vê-la fora do retrato da mulher pobre e favelada a ser tutelada:

Circulei o meu olhar pela plateia, contemplando aquela gente bem nutrida, bem vestida. Ouvindo a palavra fome, abstrata para eles [...] Eu estava confusa naquele núcleo. Percebi que a Dona Elite encara o problema da favela com vergonha. É uma mancha para um país. [...]. Não adianta falar da fome com quem não passa fome. (JESUS, 1961, p. 180).

Mesmo com o pouco interesse do público em ver o retrato exposto por Casa de Alvenaria, desenhando uma elite para quem a fome é uma abstração, Carolina Maria de Jesus persegue o seu projeto literário que se confunde com a busca por um espaço seu, onde poderá viver até sua morte em 1977. Ela não assistiu ao fim da ditadura militar, nem à criação do Movimento Negro Unificado, no qual Lélia Gonzalez teve papel fundamental, um ano depois, nem o impacto do seu livro sobre as inúmeras intelectuais e escritoras negras que hoje reivindicam o seu legado. A justaposição entre um espaço da casa e um espaço literário que escapasse aos sistemas de dominação colonial expostos por Gonzalez e Mbembe, foi a busca ou a luta de uma vida, e essa busca/luta é o próprio espaço criado, aberto com os braços e o gesto da escrita, apostando na literatura como encontro com um outro que não se sabe quem é, mas que existe. Não deixa de ser curioso que a elite intelectual progressista dos anos 1960, ávida por um retrato da fome, não tenha se interessado pelo deslocamento do olhar da escritora que, ultrapassando as fronteiras demarcadas pelo imaginário colonial, passa a observar o que acontece no mundo da Casa de Alvenaria, do asfalto, para além dos muros invisíveis da cidade.

${ }^{3}$ Se saísse da neurose constitutiva de negação do racismo, defrontando-se com o recalcamento, como escreve Gonzalez? (GONZALEZ, 1984, p. 6).
O que aconteceria se essa elite se deixasse ser olhada? ${ }^{3}$

Em 1964, três anos depois do lançamento pouco divulgado de Casa de Alvenaria, a escritora Clarice Lispector lança o romance A paixão Segundo G. H. Na conhecida carta a possíveis leitores que abre o romance, além de dizer que "ficaria contente se [o livro] fosse lido apenas por pessoas de almas formadas", descreve essas pessoas como sendo aquelas que sabem que a aproximação do que quer que seja faz-se gradualmente e penosamente - "atravessando inclusive o oposto daquilo que 
se vai aproximar". Qual a penosa aproximação que está em jogo aqui?

O romance passa-se todo dentro de um destes espaços marcados pelo princípio de segregação que marcou a arquitetura da colonização escravagista: o quarto de empregada. Projetados nos fundos dos apartamentos da classe média e alta dos espaços urbanos, próximo à cozinha e à área de serviço, mal ventilados e por vezes sem janelas, esses quartos são, como diz o título do livro da historiadora Preta Rara, no qual reúne depoimentos de trabalhadoras domésticas no Brasil, a senzala moderna (2019). No romance de Lispector, a arquitetura do quarto é uma das forças de estranhamento com a qual a narradora e protagonista G. H. se depara, e que produzirão a violenta experiência de despersonalização que ela tenta narrar a um leitor imaginário ao longo do livro.

Algo se passa naquele quarto, um dia depois que a proprietária do apartamento, G. H., demite a empregada doméstica e decide arrumar o quarto dos fundos. Já na entrada do cômodo G. H. se dá conta de que aquele espaço divergia "tanto do resto do apartamento que para entrar nele era como se eu antes tivesse saído de minha casa e batido a porta" (LISPECTOR, 2009, p. 41).

O quarto era o oposto do que eu criara em minha casa, o oposto da suave beleza que resultara de meu talento de arrumar, de meu talento de viver, o oposto de minha ironia serena, de minha doce e isenta ironia: era uma violentação das minhas aspas, das aspas que faziam de mim uma citação de mim. O quarto era o retrato de um estômago vazio. (LISPECTOR, 2009, p. 33).

Essa vida entre aspas é a que determina a sua existência como uma mera citação de algum modelo de mulher da elite, escultora não profissional, "uma réplica bonita", marcada pelas iniciais no "couro das valises", que lhe conferiam uma forma humana em vias de ser desmontada no momento em que entra no quarto de empregada. Dessa forma humana, fazia parte a ideia de uma certa estabilidade, ligada a uma "terceira perna" invisível, refletida pelo apartamento na cobertura, onde tudo "é a réplica elegante, irônica e espirituosa de uma vida que nunca existiu em parte alguma" (LISPECTOR, 2009, p. 29). O processo começa quando, G. H., começa a arrumar a casa pelo fim, "pela 
"cauda". Nesse momento, mesmo antes da entrada no quarto, ao olhar o lado de dentro do edifício, a narradora começa a experimentar "uma falta de sentido" que é a "assustadora certeza de que ali há o sentido". Tudo isso se amplia quando do umbral do quarto percebe o território desconhecido, arrumado pela empregada que arrumara o "quarto à sua maneira e numa ousadia de proprietária" o havia "espoliado de sua função de depósito", abrindo nele algo próximo a um abismo: "Da porta eu via agora um quarto que tinha uma ordem calma e vazia. Na minha casa fresca, aconchegada e úmida a criada sem me avisar abrira um vazio seco. (LISPECTOR, 2009, p. 37).

Completando o vazio aberto, em uma das paredes brancas que lembrava a de um hospital de loucos, G. H. com "surpresa e recuo" se depara com um mural, onde, à carvão, se encontrava o desenho do contorno de um "homem nu, de uma mulher nua e de um cão que era mais nu do que um cão" (LISPECTOR, 2009, p. 40). O desenho a olhava, e a fez subitamente se sentir coagida diante da lembrança da empregada ausente de quem já não conseguia se lembrar do rosto, apesar de se lembrar de seu nome: Janair.

A partir daí, nas páginas que se seguem, antes do surgimento da barata e do transe que acompanhará esse encontro, G.H. relembra do silêncio e da invisibilidade que circunscrevia o trabalho e a presença de Janair em sua casa. Ela se dá conta do ódio que estava carregando. Um ódio de que, a princípio, a narradora diz ter sido objeto, para, em seguida, dar-se conta de ter sido agente:

Percebi então que estava irritada. O quarto me incomodava fisicamente como se no ar ainda tivesse permanecido o som do riscar do carvão seco na cal seca. O som inaudível do quarto era como o de uma agulha rodando no disco quando a faixa de música já acabou. Um chiado neutro da coisa era o que fazia a matéria do seu silêncio. Carvão e unha se juntando, carvão e unha, tranquila e compacta raiva daquela mulher que era a representante de um silêncio como se representasse um país estrangeiro, a rainha africana. E que ali dentro de minha casa se alojara, a estrangeira, a inimiga indiferente.

Perguntei-me se na verdade Janair teria me odiado - ou se fora eu, que sem sequer a ter olhado, a odiara. Assim como agora estava descobrindo com irritação que o quarto não me irritava apenas, eu o detestava, àquele cubículo que só 
tinha superfícies: suas entranhas haviam esturricado. Eu olhava com repulsa e desalento. Até que me forcei a um ânimo e a uma violência: hoje mesmo aquilo tudo teria que ser modificado [...]. Uma cólera inexplicável, mas que me vinha toda natural, me tomara: eu queria matar alguma coisa ali (LISPECTOR, 2009, p. 42).

Entretanto, esse desejo de matar que era também o de retomar a posse do quarto não se realiza. $\mathrm{O}$ ódio acordou os nervos e a tranquilidade elegante da réplica em montagem humana e começou a vibrar. G. H. conta então que nesse momento, sem que soubesse, já apareciam "os primeiros sinais de desabamento de cavernas calcárias subterrâneas, que ruíam sob o peso de camadas arqueológicas estratificadas" (LISPECTOR, 2009, p. 43). Entrar no quarto não significou uma reapropriação, mas uma queda e um confinamento do qual já não conseguiria sair. Não que estivesse presa "mas estava localizada. Tão localizada como se ali me tivessem fixado com o simples e único gesto de me apontar com o dedo, apontar a mim e a um lugar." LISPECTOR, 2009, p. 49).

G. H. irá passar a maior parte do romance, deitada no chão do quarto, entre o armário e a porta, depois de tropeçar ao ver sair de dentro do móvel uma barata. A lembrança da "invisível presença" de Janair, que vai aos poucos tomando forma, com seus "traços de rainha" e o ódio que desperta os nervos ao ser ver representada na parede, dá início a um desmoronamento da montagem humana e a partir daí o desejo e a necessidade de relação desesperada, com a barata, com o possível leitor, como um "precisar sentir e fazer sentido": abertura radical, em que a inumanidade da barata parece reinscrever a humanidade de G. H. Aqui não há transcendência possível: como aponta João Camillo Penna (2010, p. 87), a abertura para o mundo implica o fracasso de um projeto teológico da encarnação. Esse fracasso se desdobra também na impossibilidade de a narradora resolver o que fazer dessa experiência. Esquecer e retomar a montagem humana e abandonar o quarto, arranjar modos de narrar de forma a nomear e assim tornar a dominar o que transbordou? Essas questões não se resolvem no romance, assim como não somos capazes de imaginar o rosto do leitor a quem ele se dirige.

No artigo “O talking back da 'negra africana': o ser desencarnado e silenciado da empregada doméstica Janair 
4 "a gesture of defiance that heals" (HOOKS, 1989, apud Pires 2019, p. 175 tradução nossa). em A paixão segundo G. H.", Francisco Pires (2009) analisa de que forma o locus de enunciação de Janair no romance de Lispector pode ser pensado como um terceiro espaço “à espera da ocupação de um saber historicamente desautorizado e silenciado em debates políticos e acadêmicos" (PIRES, 2019, p. 171). Segundo o autor, a presença de Janair em A Paixão Segundo G. H. realiza o que bell hooks chama de talking back: "uma forma de expressão capaz de ativar afetos e fraturar o campo da representação." (PIRES, 2009 p.175). O talking back seria um gesto de desafio que cura. ${ }^{4}$ Em 2019, a escritora Tamyres Batista lançou o texto dramatúrgico Caderno de receitas de Janair, no qual a personagem da empregada doméstica conversa com a plateia. A personagem Janair inicia o texto contando da sua relação com o espaço da cozinha e do quarto na casa de G. H. (BATISTA, 2019, p. 1). O que pretendemos aqui ressaltar é como essa não relação, marcada pelo racismo e pela desigualdade, depende de uma disjunção do corpo no espaço em que é preciso não ver, não ouvir, não sentir e, sobretudo, não se deixar olhar. Viver na cobertura, longe do chão e ainda assim não habitar a própria casa, como era o caso de G. H. No entanto, algo se passa no momento em que a narradora se sente olhada pelo desenho à carvão na parede do quarto de empregada que acredita ter sido feito por Janair. Algo se abre que prende o seu corpo àquele espaço, fazendo-o desmoronar. Ali é quando finalmente G. $H$. sente o chão, reconhecendo o que estava invisível e silenciado dentro de sua própria casa. Esse encontro não se dá sem uma desmontagem de sua própria forma humana, e sem o desabamento de uma subjetividade que se descobre simulacro de um modelo baseado no ocultamento e na segregação. Aqui tudo se torna espaço.

Seriam Casa de alvenaria e A paixão segundo G.H. nas suas impossibilidades de criação de um espaço de relação narrativas distópicas? Ou seria o fracasso a própria criação de um espaço de coexistência da diferença? O que é que nosso imaginário, ainda demarcado pelas fronteiras necropolíticas, não nos deixa entrever? Em Políticas da inimizade (2016), Mbembe retoma a concepção de vida em Fanon, como a possibilidade de estar aberto ao outro e ao mundo. Seria do reconhecimento de não estar só, que se poderia "corrigir a assimetria da relação, introduzindo-lhe uma dimensão de reciprocidade." (2016, p. 12). Era preciso para se dar conta disso, abandonar a ficção do 
colonizador que havia conformado os corpos e a pele dos colonizados. No caso das pessoas escravizadas, criando uma noção de vida que "remetia a um corpo sem mundo e sem terra, um corpo de energia combustível, uma espécie de duplo da natureza que era possível transformar, pelo trabalho, em stock ou fundo disponível." (2016, p. 23).

Essa impossibilidade relacional assumida por G. H., mesmo quando não observada por seus leitores, nos indica que ainda existimos no seio dessa história, ou que, ao contrário, é aí mesmo onde desistimos ou des-existimos. Nossas vidas valem ou não dentro desse eixo narrativo. Grosso modo, estamos, sim, predestinados ao desaparecimento, desde que entendamos que somos o próprio lugar de origem onde tudo desde sempre desapareceu. Lugar de desaparecidos. Magia de desaparecimentos.

Nessa fragilidade ou vulnerabilidade onde muitos podem desaparecer, reside, no entanto, o bom funcionamento do sistema. Nele se alojando o inimigo sob a forma da competição e da figura do competidor. Formas que vão se tornando não tão angustiadas, como em G. H., mas até mesmo plácidas ou totalmente aceitáveis. Se aceitável porque inevitável, ou aceitável porque intolerável, não se sabe. Ambos os extremos conjugam-se nesse jogo de fusões e incorporações que vão fazendo da vida empresarial, empreendedora e produtiva contemporânea um algo que brilha, tanto quanto ofusca.

Se competir significa todo o tempo a possibilidade de perder o job, logo perder a casa, a escola dos filhos, as relações de amizade e o respeito próprio e do mundo, estamos presos a uma rede de constante mortificação. Tratando-se sempre de perder o lugar e advir de novo o homem sem lugar, como previa Fanon. Essa lógica, que determina as relações de sociabilidade em nossas sociedades, não diminuiu. Ela apenas permitiu, sob o distanciamento do outro, distanciarmo-nos da possibilidade de um em-comum, ou de um Todo-Mundo. Ao nos distanciar, entendemos, vivemos e sentimos o que chamam solidão como sendo, de fato, o modo de organização das vidas contemporâneas, sua lógica de inimizade e sua necessidade de fragilizar os laços de amizade e o imaginário comum, fontes inevitáveis dos discursos e das sensações de distopia atuais. 


\section{Poéticas da Relação}

Todo o convite que faz Glissant a uma poética (1990) e a uma filosofia da Relação (2009) é em prol de uma lógica que não essa do isolamento ontológico do indivíduo, e da eliminação de sua parte comum a todos os "outros" da terra. Isso, para ele, só se perfaz se sairmos das identidades de raiz única, formadoras dos estratos territoriais da nação, de suas conquistas calcadas na dominação e na anexação dos corpos, territórios, línguas e subjetividades. Logo, todo um determinado imaginário do idêntico e do mesmo como seu correlato, transparente e claro (2009, p. 69). A relação, ao contrário disso, envolver-nos-ia todos na tarefa de trato com a opacidade, com o desconhecido, com a imprevisibilidade e, sobretudo, com o risco constante da diluição no outro, risco que só pode se dar se elaboramos ou atravessamos esse sedimento primordial da angústia de aniquilamento. Um dos modos de ultrapassar o perigo da angústia, transmutando-o em risco de contato, se dá através da constituição do que Glissant chamaria de "lugar de origem" (2009, p. 46). O lugar de origem não é fixo, nem essencial. Ele é, no imaginário-arquipélago desse pensador da Martinica, algo incontornável em seu duplo aspecto: incontornável porque nunca conheceremos todo ele, nunca daremos a volta nele todo, mas sempre, de um ou de outro modo, o portaremos conosco (2009, p. 87). Essa dupla valência do lugar de origem institui em sua própria constituição o gérmen de uma filosofia da Relação. Posto que também opaco, e não apropriável em sua totalidade, o lugar de origem porta uma abertura ou fenda que impossibilitaria o seu fechamento circular e insular. Obrigando-nos não apenas a abrir a porta do quarto de empregada, mas a derrubar os seus muros. Saída e contraposição radical ao homem sem lugar de Fanon (FANON, 2011, apud MBEMBE, 2016).

Nas poéticas relacionais, o lugar de origem deve poder se estabelecer, identidades sólidas devem existir para não se aniquilarem ou se diluírem totalmente. Nesse contexto, é o homem sem lugar que deverá desaparecer. A impossibilidade dessa constituição, como observamos até agora ser o caso das sociedades de traço colonial, cria poéticas da Relação desiguais, gestadas em processos de amargura e de dor. A não reciprocidade impede a constituição de lugares suficientemente 
${ }^{5}$ Sabemos que havia a preocupação e a precaução de não colocarem na mesma barca, logo no mesmo destino, pessoas escravizadas pertencentes à mesma nação, fazendo com que esse contato e relação entre eles fossem desafiados também, pelo desconhecido, o difícil e o incomunicável. Importante frisarmos como esse empreendimento colonial é matriz posterior dos mais diferentes regimes de apartheid, exclusão e totalitarismos fazendo com que a impossibilidade de relação e formação de elo entre os subalternizados seja o ponto nevrálgico de fragilização de suas próprias vidas. opacos, e, ao mesmo tempo, sólidos. Entendendo que identidade é também opacidade, porque ela mesma é fruto da relação. Fazendo com que a força desse homem crioulizado da relação não esteja em sua transparência e clareza, mas em sua opacidade. Sob o ponto de vista colonial, no qual prevalece a identidade-raiz, a clareza e a transparência vêm representando a possibilidade de dispor do outro, mais próximas aos fenômenos da invizibilização, a transparência é um modo de exterminar sem que seja visto, sem que fique o rastro. Aqui entra a função maior das poéticas e do pensamento da relação - prover rastros e abrir caminhos residuais como modos de reparação de longo termo e sem garantia, mas fundamentais para que o imaginário possa ir funcionando noutra frequência. A do encontro mesmo quando em sua ausência, a da ferida do não encontro mesmo quando em sua promessa, a da conscientização afetiva desse fim como traço de um início negado, extirpado, como indica Glissant nesse texto poético, ficcional e teórico "A barca aberta" (1990, p. 17-21).

A barca é concreta e imaginada pelo poeta. Ela é a que trouxe os seus ancestrais da África para serem escravizados nas colônias da América. Para o autor, ela é constituída por três diferentes abismos: no primeiro deles, ela é o abismo do próprio ventre. Um ventre doloroso e paradoxal, onde se impunha uma nova vida, desconhecida e sem vínculos, feita do abandono forçado de tudo o que ficou para trás: família, língua, terra, costumes, comidas, cheiros, laços. ${ }^{5} \mathrm{E}$ ao mesmo tempo a morte. Uma morte todo tempo real - presente nos suicídios no meio do mar, de muitas das pessoas negras, presas como escravas nessa barca-ventre, mas ainda nas doenças geradas pela degradação, descuido e abandono dessas vidas no porão escuro da longa travessia da barca. Esse é o primeiro gesto do escritor: abrir esse ventre. Abrir o quarto dos fundos. Escrever como ele é feito de fluxo de vida e resistência, de um ser-sendo (GLISSANT, 1990, p.200-201) que porta, ao mesmo tempo, o gérmen da morte ali inscrito. Uma espécie de espaço natimorto, ou de vida abortada. Sob esse prisma, se nos parece ainda crucial escrever esse não mundo do ventre da barca em contraposição à narrativa do Novo-Mundo. Imaginemos que é aí onde estaria todo o princípio de um espaço literário não diluidor do outro, mas em relação de imprevisibilidade total para com ele. 
O segundo abismo caracteriza-se pelo próprio mar. O mar encarna o desconhecido e o infinito - a possibilidade do fim, mas também a abertura. Havendo algo que o constitui como esse espaço liso sobre o qual se desliza, se perde, mas também por onde se cria e regenera. Não por acaso, as narrativas afrodiaspóricas farão do mar uma divindade fundacional: Iemanjá, o orixá feminino do mar, estará presente de forma crucial na organização das comunidades que em toda a América negra irá se rebatizar, se reinventar e reexistir. Esse oceano passa a desenhar o inconsciente negro da América, o inconsciente de todos nós que do lado de cá buscamos o fio da vida e sua palavra errante. $\mathrm{O}$ terceiro abismo é ele também constitutivo de um modo muito particular dessa usina inconsciente, porque ele é a perda de tudo o que é familiar. A barca é o lugar onde tudo se estranha. É também a constituição de um nós-mesmos como estranhos. Corpo negro escravizado como sendo o primeiro estranho-familiar que funda o inconsciente da América. Para Glissant (1990), é desse lugar, desse topo, onde vai se abrir e se liberar o saber da Relação. É do abismo onde vai se conhecer um Todo-Mundo, nas múltiplas línguas e culturas afro-diaspóricas ali misturadas. $\mathrm{O}$ abismo será visto pelo autor também como perspectiva e projeção - um modo de conhecimento do desconhecido que só uma certa inversão da topologia da utopia poderia cunhar. Desse modo, uma das distopias do presente seria negar esse topo da barca, do navio negreiro, sua existência e lugar fundacional do espaço discursivo, logo artístico e literário entre nós. O contrário disso seria fazer desse desconhecido o conhecimento partilhado. Há uma nota de rodapé no texto "A barca aberta" que merece atenção primordial:

\footnotetext{
${ }^{6}$ A imagem, irreproduzível na forma tipográfica dos ícones foi assim desenhada por Glissant:

7 Texto traduzido por Manuel Mendonça e com divulgação online autorizada pela Editora Sextante.
}

O Tráfico passa pela porta estreita do barco negreiro, cuja esteira imita a reptação da caravana no deserto. A sua figura seria a seguinte: --)---(--. ${ }^{6}$ A leste, os países africanos, a oeste as terras americanas. Esse animal tem o aspeto de uma fibrila.

As línguas africanas desterritorializam-se, para contribuir para a crioulização no Ocidente. É o choque mais totalmente conhecido entre os poderes do escrito e os impulsos da oralidade. No barco negreiro, o único escrito é o livro de contabilidade que diz respeito ao valor de troca dos escravos. No espaço do barco, o grito dos deportados é abafado, como o será no universo das Plantações. Este choque ecoa até nós. (GLISSANT, 2011, p. 30). ${ }^{7}$ 
8 "Arquivo-corpo" é uma noção em desenvolvimento no trabalho de Ana Kiffer, que indica não apenas o apagamento dos traços arquivísticos nos diferentes regimes de extermínios cometidos na sociedade brasileira, mas também como um grande conjunto da cultura que não ingressou no sistema escriturário vem, através da materialidade dos corpos e seu sistema próprio de inscrição, compondo um arquivo da diversidade a ser cada vez mais considerado no seio das pesquisas letradas.
Destaquemos em primeirolugar esse livro decontabilidade dos corpos escravos como sendo o único registro da escrita no mundo da barca. Poderíamos dizer dessa barca-mundo cujo grito sem palavra ainda ecoa entre nós. Aliás, assinalemos a forma grito como sendo o traço presente e permanente da expressão dessa língua não escrita, resíduo dos corpos escravizados e contabilizados, de vidas e horas contadas. Esse livro de contabilidades é o rastro do tanto que carregamos do não escrito como marco do nosso espaço literário. Ele funciona como essa espécie de registro mortuário, e ao mesmo tempo prova cabal, não apenas da atrocidade do sistema escravocrata, mas dos devires dessas línguas faladas desde aqui - que deveriam cada vez mais serem ouvidas como modos de pensar distintos desse grande edifício ruinoso do ocidente. Todos os restos - ruínas, corpos, arquivos sem livros, cadernos e traços, pruridos e notas que ecoam ainda entre nós são os gritospalavras desse livro de registros sem registro, dessa escrita sem letra, desses arquivos-corpos ${ }^{8}$.

\section{Questões em aberto pela barca entre nós aberta}

Essa barca-mundo transita ainda entre nós como um espaço heterotópico, sem lugar, mas nem por isso distópico. Espaço também resistente a funcionar no impossível do utópico, ou quando por aí adentra é para confirmar o fantasma assassino que paira sobre os modos de relação constitutivas de uma certa utopia nos espaços coloniais. A quantidade de feridas que carrega a barca aberta desenha todo o escopo da discussão que vimos aqui encetando. Entendendo que o redesenho do em-comum (MBEMBE, 2019), ou de que a construção de um Todo-Mundo (GLISSANT, 1997) implicaria, necessariamente, uma revisão aguda das separações entre as pessoas, os povos, vivos e não vivos que habitam esse planeta, e a de que esse redesenho é ele mesmo uma operação de corte. Uma das hipóteses que levantamos é de que hoje esse corte ou essa necessidade de cortar e de separar delimitam os pontos de ancoragem dos nossos não pertencimentos ao mundo e à representação de mundo que até agora se nos foi oferecida. Esses cortes que vêm se apresentando ao mundo podem, eventualmente, se fazerem como cenas de seu próprio fim. Como se um dos modos da distopia atual funcionasse sob a 
9 Ou como disse Mbembe : C'est pourquoi, dans la redéfinition d'une politique du bien au-delà de l'humain, penser e panser sont indissociables (MBEMBE, 2020, p. 54)

10 Sabemos que anatomia em grego antigo significa cortar em partes. perda da ideia de que estávamos todos juntos. Buscamos alertar que, no entanto, não estávamos todos juntos. De que o porão nunca foi o convés e vice-versa, e de que o quarto de empregada continua invisível, com seus muros ainda edificados.

Sob esse prisma, manter essa invisibilidade é um modo de organizar o discurso sobre a distopia desde o convés, ditando o como deveríamos "estarmos juntos". Há também, evidentemente, a perda da ilusão de que estávamos todos juntos, e nesse sentido os gestos de corte que insurgem hoje nas sociedades contemporâneas, fazendo parecer que o mundo nunca mais andará sob um só e mesmo trilho, vêm sendo responsabilizados pelo fim de uma união. União que era, entretanto, ilusória e falaciosa, apontando para o fim de uma utopia e sua consequente distopia.

Cortar os modus operandi em escala global implica trazer necessariamente à tona a aflição e as feridas (cortes) de um estar junto que funcionava de maneira fusional. Onde um obrigatoriamente se diluía num outro, sempre mais forte, sólido e poderoso. Foi essa mesma ideia de fusão que fez com que demorássemos para começarmos a buscar os contornos de nossas separações, porões e quartos fechados. O contorno de muitos dos nossos lugares de origem. Por isso até mesmo os escrever é ainda agora uma operação de corte, logo uma ferida sobre a ferida anterior, como vimos tão presente na escrita de Lispector e na opacidade de Glissant, mas essa é também, como entendemos, a nossa única possibilidade de cicatrização. Já que cicatrizar pode ser ter que manter a ferida aberta e lidar com ela pelo maior tempo possível. ${ }^{9}$ É sob este prisma que esse texto aposta numa imaginação radical da relação entre os povos e as pessoas, entre vivos e não vivos, humanos e não humanos como operações escriturárias que são cortes, refazendo anatomias ${ }^{10}$ (in)sensíveis que desenharam, desse modo, os nossos corpos. A Relação principia no corte, e na tomada em nossas mãos de suas feridas. Investimos nessa potência da imaginação como modo de atravessar as separações necessárias, e apostar em outros encontros possíveis. Percebemos também que para poder imaginar radicalmente um espaço relacional é preciso, necessariamente, alargar a sua dinâmica para além do humano e do vivo. A relação com a barata clariceana, com a casa e a alvenaria em Jesus, ou com o mar e a barca glissantianos operam e instauram essa mesma dimensão. 
11 De nos jours l'identité tend en effet à devenir le nouvel opium des masses.

Il en est ainsi parce que la raison comme faculté humaine universelle est assiégée et que le modèle de la démocratie libérale supposée en être l'une des manifestations est partout en crise. La plupart des antagonismes politiques s'expriment de plus en plus sous une forme viscérale. Les crispations identitaires sont des symptômes de cette entrée dans l'ère de la viscéralité. (ibidem, p. $52-53)$.
Sob esse aspecto, a relação em sua lógica própria faz ceder o espaço antes consagrado à razão humana como único comandante de uma política entre os vivos. A razão será chamada a um convívio outro com e entre os afetos, as sensações e as intuições que ocupam a Relação. Esta que não conhecemos, escapando ao contorno do que se define como humano, até aqui circunscrito em grande parte pelo exercício da razão ou pela aparição de seus opostos. Nesse ponto, assinalamos, diferente de Achille Mbembe (2020), que a presença dos afetos e que a constituição do próprio afeto não deve ser vista sob o prisma de sua antagonização para com universo da razão. Está em jogo aqui outra concepção de racionalidades alternativas. Onde os afetos não insurgem apenas como metáforas das tripas e das visceralidades obscuras $^{11}$ (MBEMBE, 2020, p. 53, 184-186). Decerto essa vivência se presentifica, incluso porque nunca fomos capazes de viver em-comum os nossos afetos constitutivos. Em parte, essa dificuldade é hoje estimulada pelo próprio funcionamento do sistema capitalista ultra neoliberal, que "para se impor como uma religião deve continuar apaziguando as preocupações, medos e sofrimentos desses que mantém sob suas garras." (MBEMBE, 2020, p. 185, tradução nossa). Ou seja: jogando ou camuflando aquilo que é, no entanto, partícipe da presença dos afetos - trazer à tona conflitos e diferenças constitutivas. Mas essa dificuldade também advém do processo de atualização constante da matriz colonial do mundo, dessa angústia de aniquilamento que é ela mesma um excesso oriundo da ausência da existência afetiva do outro em nós. Ausência de Relação que prospectamos na constituição do outro como exterior e inimigo. Carregando a existência afetiva de um teor tipicamente traumático e invasivo. Fazendo com que a mesma só possa ser vivida na diluição (fusão) que nos destrói, ou na visceralidade que incute a necessidade de destruir o outro. A carga afetiva atual é também a cena disso tudo que foi recalcado como possibilidade do afeto em constituir sua luta na manutenção da própria vida. Sua existência como base dos processos de Relação.

Por isso, também é importante pensar que esse apoio à vivência dos afetos como visceralidades e passionalidades destruidoras do outro se acelera quando essa própria matriz 
colonial e/ou ultra neoliberal se vê ameaçada através de outras redes de solidariedade afetiva, ou quando pontos fulcrais de sua vulnerabilidade são deflagrados. A distopia, sob esse ângulo, deveria ser também imaginada como um modo de reação dessa matriz, quando deflagrada em sua própria vulnerabilidade. Sendo assim, ela é também um convite para re-imaginarmos de forma radical o mundo, o espaço, o tempo, enfim, os modos das relações e seus afetos constitutivos. Por outro lado, se seguimos as pistas deixadas por Carolina Maria de Jesus, Lispector e Glissant, o espaço literário deveria ser repensado já não apenas como espaços e reservatórios utópicos de uma sociedade, mas como lugar de desorientação, choque e corte. Porão ou quarto de empregada. Espaços que podem abrir uma passagem, ali onde as fronteiras necropolíticas foram instaladas com seus mecanismos de vigilância e aniquilamento de corpos dissidentes. Espaços onde se faz possível olhar para o que se ocultou. Enfrentando as suas claustrofobias e enclausuramentos, eficazes e contundentes em nos mostrar como esse espaço literário não respirou a barca-mundo aberta, crioula e diversa das Américas. O choque com a escassez do escrito na constituição dos espaços coloniais impõe a necessidade de se reabrir o livro de contabilidade do porão da barca, ela mesma por fim aberta. O caminho estrangulado dos rastros e das angústias de aniquilamento, que constituem esses espaços de clausura são, de fato, o lugar da abertura, da fenda inicial de uma poética da relação. Sua força, se não destitui, ao menos vulnerabiliza os messianismos negativos e as crenças de que o fim do mundo é o que nos resta. $O$ fim do mundo é o nosso resto, traço, rastro. Vimos sendo esse próprio fim, começamos por ele, ou como disse Glissant: com o corpo de tudo despido, do homem negro que aqui aportou (GLISSANT, 1990). Escrever significaria não vestir nem despir, mas formular outra teoria da ferida da exposição da carne e da expropriação dos corpos, própria ao mundo colonizado, distinta dos cosmopolitismos hoje impotentes e distópicos da razão branca e ocidental. 


\section{REFERÊNCIAS}

BATISTA, Tamyres. Caderno de receitas de Janair. Disponível em: <https://elastramam.wordpress.com/2019/10/07/outrastramas-caderno-de-receitas-de-janair-tamyres-batista/ $>$. Acesso em 20/11/2020

BLANCHOT, Maurice. L'espace littéraire. Paris: Gallimard, 1955.

BUARQUE DE HOLANDA, Sergio. Raízes do Brasil. São Paulo: Compahia das Letras, 1995.

FOUCAULT, Michel. Le Corps utopique et les hétérotopies. Posfácio Daniel Defert. Paris: Nouvelles Éditions Lignes, 2009.

FREITAS, Kenia; MESSIAS, José. O futuro será negro ou não será: Afrofuturismo versus Afropessimismo. As distopias do presente. Imagofagia, n. 17, 2018. Disponível em: <http:// www.asaeca.org/imagofagia/index.php/imagofagia/article/ view/1535>. Acesso em: 11/02/2021

GLISSANT, Edouard. Poétique de la Rélation - poétique III. Paris: Gallimard, 1990.

"A Barca Aberta". In: Poética da Relação. Rio de Janeiro: Sextante Editora, 2011, 17-30. Tradução de Manuel Mendonça. Disponível em: <https://rebeldesistematico.files.wordpress. com/2016/11/a-barca-aberta.pdf $>$. Acesso em: 25 nov. 2020.

Philosophie de la Relation. Paris: Gallimard, 2009.

. Traité du Tout-Monde. Paris: Gallimard, 1997.

GONZALEZ, Lélia. Racismo e sexismo na cultura brasileira. Revista Ciências Sociais Hoje, Anpocs, p. 223-244, 1984. Disponível em: <https://edisciplinas.usp.br/pluginfile.php/4130749/ mod_resource/content/1/gonzalez.lelia\%281983-original\%29. racismo\%20e\%20sexismo\%20na\%20cultura\%20brasileira_1983. pdf> Acesso em 11/02/2021

JESUS, Carolina Maria de. Quarto de despejo (diário de uma favelada). São Paulo: Editora Francisco Alves, 1960. 
. Casa de alvenaria: diário de uma ex-favelada. São Paulo: Editora Paulo de Azevedo, 1961.

KIFFER, Ana; GIORGI, Gabriel. Ódios políticos e política do ódio. Rio de Janeiro: Bazar do Tempo, 2019.

KRENAK, Ailton. Ideias para adiar o fim do mundo. São Paulo: Companhia. das Letras, 2019.

LISPECTOR, Clarice. A paixão segundo G. H. Rio de Janeiro: Rocco, 2009

MBEMBE, Achille. Necropolítica: biopoder, soberania, estado de exceção, política de morte. São Paulo: n-1 edições, 2019.

Brutalisme. Paris: La Découverte, 2020.

Politiques de l'inimitié. Paris: La Découverte, 2016.

MORSS, Susan Buck. Hegel e Haiti. Novos estudos Cebrap. Edição 90. v. 30, Julho de 2011. p. 131-171. Disponível em: $<$ http://novosestudos.com.br/produto/edicao-90/> Acesso em: $11 / 02 / 2021$

PENNA, João Camillo. O nu de Clarice Lispector. Alea - estudos neolatinos. v. 12, n. 1, p. 68-96, Rio de Janeiro, 2010. Disponível em: <https://www.scielo.br/pdf/alea/v12n1/v12n1a06.pdf>. Acesso em: 11/02/2021

PIRES, Francisco Quinteiro. “O talking back da 'negra africana': o ser desencarnado e silenciado da empregada doméstica Janair em A paixão segundo G. H". Brasiliana: Journal for Brazilian Studies. Vol 8, n.1-2, p. 167-189, 2019.

RARA, Preta. Eu, empregada doméstica. A senzala moderna é o quartinho de empregada. Belo Horizonte: Letramento, 2019.

SISKIND, Mariano. Rumo a um cosmopolitismo da perda: ensaio sobre o fim do mundo. trad. de Caio Cesar Esteves de Souza. Copenhague / Rio de Janeiro: Zazie Edições, 2020.

THRIFT, Nigel. Non-representational theory: space, politics, affects. Londres/Nova Iorque: Routledge, 2008. 


\section{ABSTRACT \\ Dystopia, the Anguish of Annihilation and the Radical Poetics of Relation}

This article reflects upon dystopia through the lens of the anguish of annihilation (MBEMBE, 2016), and ponders how this notion challenges the emergence of poetics of relation (GLISSANT, 1990) as a way of creating utopic and heterotopic (FOUCAULT, 2009) literary spaces (BLANCHOT, 1955), in societies whose colonial past, and authoritarian incursions, have been perpetrated over centuries, as is the case of the Brazilian society. The primary hypothesis is that, in these contexts, the spaces of dystopia are established as the beginning, and not as the end of everything, becoming one of the foundational operators of a place (utopic or heterotopic?) created by the other, the colonizer. The anguish of annihilation is the primary tool for the construction of this place and this scene (which literature will propagate), and of the social ties and the effects of the subsequent spatial (social) and discursive division. In this sense, the article will question the contemporary notion of dystopia - constantly present in the narratives about the end of the world and in the arising of contemporary negative messianisms in the specific context of the formation of colonial societies, but not without observing some aesthetic-political strata in which a poetics of the relation outwit this design in post-colonial societies.

Keywords: Dystopia. Poetics of Relation. Literary space. Brazil. 
Ana Kiffer é Professora da Pós-Graduação em Literatura, Cultura e Contemporaneidade da PUC-Rio, Cientista do Estado pela FAPERJ 2019 e Bolsista de Produtividade no CNPq desde 2013. Sua pesquisa atual versa sobre os corpos e os afetos políticos, e dentro desse tema publicou em 2019 o livro Ódios Políticos e Política do Ódio, com Gabriel Giorgi pela Bazar do Tempo, Brasil, e pela Eterna Cadência, Argentina, em 2020.

Mariana Patrício Fernandes é Professora do Departamento de Ciência da Literatura e do programa de pós-graduação de Ciência da Literatura da Universidade Federal do Rio de Janeiro (UFRJ). Sua pesquisa concentra-se nas áreas de Literatura e Performance. É uma das coordenadoras do Laboratório de Teorias e Práticas Feministas do PACC-UFRJ. 